\title{
Value of pumped hydro storage in a hybrid energy generation and allocation system
}

\author{
Ayse Selin Kocaman ${ }^{\mathrm{a}, *}$, Vijay Modi ${ }^{\mathrm{b}}$ \\ a Department of Industrial Engineering, Bilkent University, Bilkent, Ankara, Turkey \\ b Department of Mechanical Engineering and Earth Institute, Columbia University, New York, NY, USA
}

\section{H I G H L I G H T S}

- We propose a two-stage stochastic mixed-integer programming model for a hybrid energy system.

- We investigate the solar and PHES integration considering the streamflow uncertainty.

- We study the benefit of PHES system over conventional hydropower systems to support solar.

- We examine the role of PHES systems in both isolated and connected systems.

\section{A R T I C L E I N F O}

\section{Keywords:}

Pumped hydro energy storage

Solar energy

Two-stage stochastic program

India

\begin{abstract}
A B S T R A C T
Transition from fossil fuels to renewable sources is inevitable. In this direction, variation and intermittency of renewables can be integrated into the grid by means of hybrid systems that operate as a combination of alternative resources, energy storage and long distance transmission lines. In this study, we propose a two-stage stochastic mixed-integer programming model for sizing an integrated hybrid energy system, in which intermittent solar generation in demand points is supported by pumped hydro storage (PHES) systems and diesel is used as an expensive back-up source. PHES systems work as a combination of pumped storage and conventional hydropower stations since there is also natural streamflow coming to the upper reservoirs that shows significant seasonal and inter-annual variability and uncertainty. With several case studies from India, we examine the role of high hydropower potential in the Himalaya Mountains to support solar energy generation in the form of pumped hydro or conventional hydro system while meeting the demand at various scales. We show that pumped hydro storage can keep the diesel contribution to meet the demand less than $10 \%$, whereas this number can go up to more than $50 \%$ for conventional systems where the streamflow potential is limited compared to the demand. We also examine the role of pumped hydro systems in both isolated and connected systems (through inter-regional transmission lines) and show that the benefit of pumped hydro is more significant in isolated systems and resource-sharing in connected systems can substitute for energy storage. In addition, with the help of the proposed model, we show that the upper reservoir size of a pumped hydro system could be lower than the reservoir size of a conventional hydropower system depending on the demand scale and streamflow availability. This means that, most of the current conventional hydropower stations could be converted to pumped hydropower stations without needing to modify the upper reservoir, leading to a significantly reduced diesel contribution and lower system unit cost.
\end{abstract}

\section{Introduction}

Current supply for electricity generation mostly relies on fossil fuels. However, fossil fuels are finite and their combustion causes global warming and health hazards. To reduce the role of fossil fuels and ease the concerns on the electricity generation, it is necessary to adopt energy models that employ renewable generation.
Integrating renewable sources into traditional power systems presents two important challenges. First, renewable sources such as solar and wind are intermittent, limiting the controllability of their power output at any given time. Second, their generative properties are heavily dependent on the spatial distribution which can lead to a mismatched between where the renewable energy potential exists and where the energy will be ultimately consumed. Delucchi and Jacobson

\footnotetext{
* Corresponding author at: Bilkent Universitesi, Endustri Muhendisligi, Bilkent, Ankara 06900, Turkey.

E-mail address: selin.kocaman@bilkent.edu.tr (A.S. Kocaman).
} 


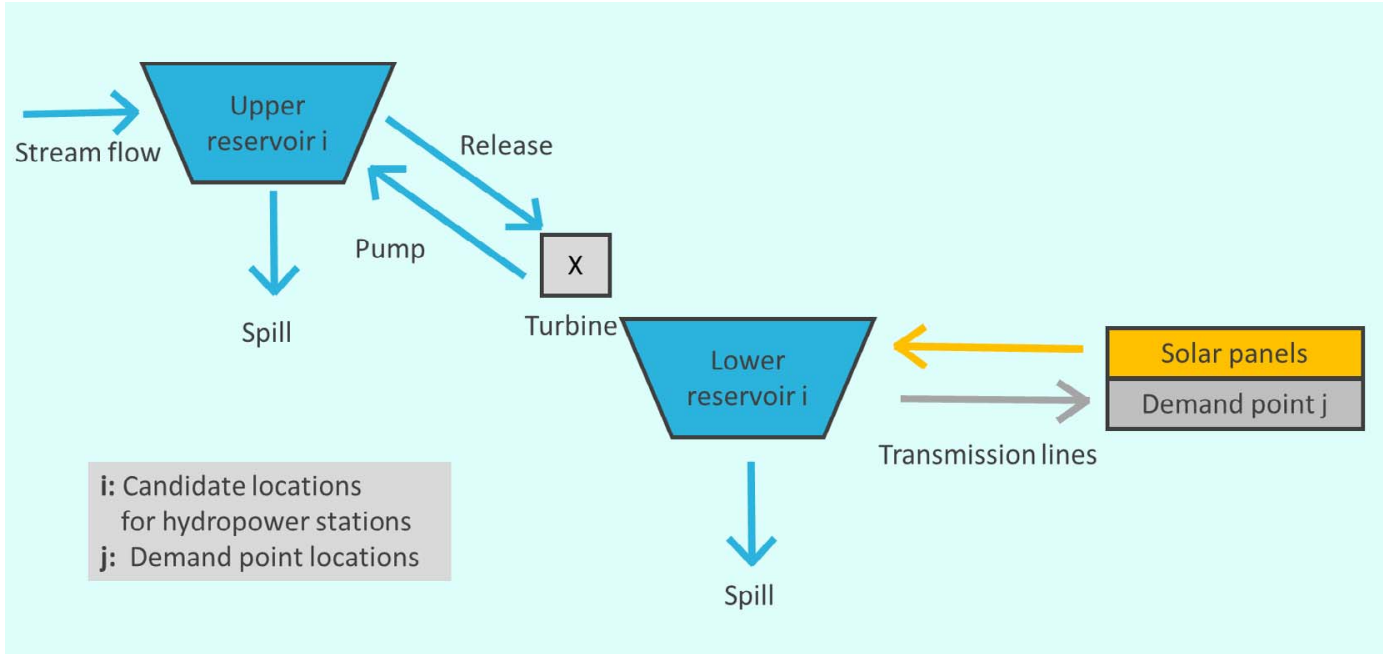

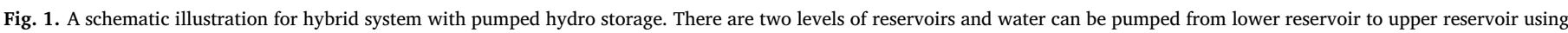
the excess solar energy.

argue in $[1,2]$ that it is possible to overcome the difficulties of working with renewables, and show that it is technologically and economically feasible to meet the $100 \%$ of the world's energy demand using wind, water and solar.

To mitigate the intermittency of renewable sources, there are several ideas proposed to design and operate cost-efficient and reliable renewable energy systems. Designing hybrid systems that operate as a combination of alternative resources, using energy storage, and building long distance transmission lines can all help ameliorate the effects of intermittent renewable generation and allow for the grid to accommodate more variation in both supply and demand $[3,4]$. Transmission lines accommodate more geographic aggregation, which smooths the variability of intermittent sources over large distances $[5,6]$. Large spatial aggregation also allows for the design of more efficient hybrid systems and the use of large-scale energy storage systems such as pumped hydro energy storage (PHES).

Optimal sizing of hybrid systems is not a trivial task, considering the uncertainties of renewable sources. Although there is vast literature on the subject, most studies approach the problem in a deterministic way by either using hourly average values of renewables $[7,8]$ or using time series that only consider variability over time [9-12]. There are a limited number of studies that focus on optimal design and sizing of hybrid systems considering these uncertainties. Stoyan et al. [13] use a scenario-based approach to consider uncertainties and propose a stochastic mixed-integer model that minimizes cost and emission levels associated with energy generation while meeting the energy demand of a given region. Powell et al. [14] model energy resource allocations with long-term investment strategies for new technologies using an approximate dynamic programming approach. Ekren and Ekren size a hybrid system that includes solar, wind and battery storage considering the uncertainty of load and resources with response surface modeling in [15] and simulated annealing method in [16]. Roy et al. [17] and Arun et al. [18] study optimal sizing of wind/battery and solar/battery systems respectively, using chance constraint programming. Kuznia et al. [19] and Kocaman et al. [20] propose scenario based two-stage stochastic programming models for the optimal design of hybrid systems with various components.

Energy storage is one of the most important components to use renewable sources effectively and finding suitable storage technology for renewable systems is an interesting problem [21]. Among the alternative energy storage technologies, PHES systems are the most widely used, especially in large-scale applications [22]. Although PHES systems are very popular and there are a vast number of studies on how vest to operate them [22], the literature on the optimal sizing of PHES systems is very scarce [23] and these studies mostly focus on wind and PHES integration [24-26]. Kapsali et al. [24] and Katsaprakakis et al. [25] take deterministic approaches and study integrated wind and PHES design problems for isolated systems. Brown et al. [26] propose a linear programming model for optimal sizing of generators and reservoirs to store wind energy. On the other hand, in [27] Ma et al. point out the scarcity of the studies on the optimal sizing and techno-economic evaluation of solar and PHES integrated systems and propose a methodology based on a genetic algorithm.

In this study, we propose a two-stage stochastic mixed-integer programming model for sizing an integrated hybrid energy system, in which intermittent solar generation is supported by PHES systems and diesel used as a proxy for an expensive dispatchable source. In this system, solar energy is generated within the demand points and extra solar energy is sent to be stored in PHES systems via bi-directional transmission lines. PHES systems are designed as a two-level hierarchical reservoir system with a combined pump and generator located between reservoirs. When the energy is stored, the water in the lower reservoir is pumped to the upper reservoir to be released again when needed. PHES systems work as a combination of pumped storage and conventional hydropower stations since there is also natural streamflow coming to the upper reservoirs that shows significant seasonal and inter-annual variability and uncertainty. A schematic illustration of our hybrid system with pumped hydro storage is given in Fig. 1.

The aim of the model is to understand the relationship between solar and streamflow patterns and determine the optimal sizing of infrastructure needed for solar and PHES systems to meet demand in a cost effective way and. Our model helps assess how efficiently solar energy could meet the electricity demand with the help of pumped hydro systems utilizing high hydropower potential of rivers.

The contributions of our study can be summarized as follows: we propose the first model that investigates the solar and PHES integration problem while taking into consideration the streamflow uncertainty for large-scale systems. With this model, we also examine the benefit of pumped hydro storage systems by comparing the results with those produced by conventional hydropower stations. We present results from several cases studies in India that help articulate the potential for hydropower sites in the Himalaya Mountains to support solar energy. In [20], conventional hydropower generation capacity along with minimal diesel usage to support $1 \mathrm{GW}_{\text {peak }}$ solar power generation is investigated and results are presented for isolated systems and connected systems (through inter-regional transmission) to show the benefits of resource-sharing and to see the effects of geographic diversity on the infrastructure sizing. In this study, we take a similar approach and 
examine the role of pumped hydro systems in both isolated and connected systems and show that the benefit of pumped hydro is more significant in isolated systems and that resource-sharing can substitute for energy storage in larger, interconnected systems (i.e. resourcesharing and pumped hydro storage work as substitutes). We also show for the first time that when solar energy capacity is co-optimized with the pumped hydro system, the amount of solar energy directly used by the demand points (without being stored) is higher than the amount of solar energy used when solar system is co-optimized by a conventional hydropower system. In addition, with the help of the model proposed, we show that the upper reservoir size of a pumped hydro system could be lower than the reservoir size of a conventional hydropower system. This means that most of the current conventional hydropower stations could be converted to pumped hydropower stations by building small lower reservoirs and reversible pumps, allowing for the hybrid systems use significantly reduced diesel amounts.

The sections of this paper are outlined as follows: A more precise statement of the problem is given in Section 2. A two-stage stochastic programming model of the described problem is provided in Section 3. Computational results along with the discussions are provided in Section 4. We conclude in Section 5.

\section{Background and assumptions}

In this paper, we are interested in optimally sizing the infrastructure of a hybrid system that includes hydro and solar energy generation and transmission lines between generation and demand points. To mitigate the volatility of supply and demand, we use reservoirs as "water storage" in a pumped hydro storage system (PHES). In our setting, excess solar energy can be used to pump water from a lower reservoir to an upper reservoir, where it is stored in the form of gravitational potential energy. There is also natural inflow of water to the upper reservoir, which allows the system also function as conventional hydropower station. In a PHES system, a generator and water turbine can be operated as a motor and pump. An expensive back-up source (e.g. diesel) is used when renewable sources are not available. The cost of diesel can also considered as a penalty for mismatched demand that is paid for each kWh of energy that cannot be met by hydro or solar.

While PHES systems hold great potential for increasing the penetration of renewable energy by transferring supply from low use periods to peak use times, they face a number of important limitations familiar to conventional hydropower installations. Hydro installations are geographically limited: they are only feasible in locations that have sufficient water available and are capable of siting large reservoirs at different heights. Different technologies (alternating current (AC) and direct current (DC)) are available that can facilitate the routing of power from the hydropower stations to demand points in a controllable fashion. For connection of remote renewables, high voltage direct current (HVDC) technology is especially well suited due to low losses and higher controllability than AC. In this problem, possible network flow directions from sources to demand points are prescribed with dedicated lines and designed as a point-to-point topology. Here, we neither model the grid itself nor consider real power flow equations and phase angle differences. We assume that power flows over lines can be independently assigned. This representation of power flows, which captures point-to-point movements without explicitly modeling the grid, is a common approximation made in policy studies $[14,20]$.

Several other common assumptions have been made to reduce the complexity of modeling hydropower components [20]. We assume that the pipe network cost is linearly dependent on the reservoir size and can be included in reservoir cost. No operational cost is assumed related to hydropower station [28]. Losses due to evaporation are neglected. The power production potential in a hydropower station depends on the flow rate of water and the potential head available. Potential head usually depends on the constructed wall of the dam and topography of the site. As in Norwegian statistics [28], we assume that the vertical height of a waterfall is measured from the intake to the turbines. Thus, we use a constant head $(100 \mathrm{~m})$ for each reservoir during the operations and do not consider the reduced electricity conversion efficiency, which is caused by reduction in the height of waterfall as the reservoir is drawn. Given that we use Himalayan sites with steep slope in our case studies, we believe that we are not far from the reality.

In this system, it is important to model energy supply and demand with hourly time periods for at least one in order to accurately capture both the hourly and seasonal variability of the sources. Here, as the solar energy can be also stored and there is significant solar radiation variability throughout the day, using hourly time increments in addressing this problem becomes even more important. An approach that avoids capturing every time increment over a year by simply sampling different time periods (e.g. different time of the years and time of the days) fails to accurately model the storage. Moreover, modeling reservoir systems is more complicated than modeling other storage types such as batteries, because reservoir storage transcends the diurnal cycle, i.e. we may put water in a reservoir storage in September so it can be used in December. In addition to the components of a conventional hydropower system model, the PHES model must also include the mass balance equations of the lower reservoir and power flows from demand points to hydro stations.

In order to capture the uncertainty, we are employing a scenario approach, which is widely accepted in the literature $[19,29]$. Here, we present a scenario-based model with multiple time periods that are coupled by storage. By scenario approach, a set of prototype 1-year series with 3-hourly time increments are determined as a particular realization of the streamflow data.

\section{A two-stage stochastic programming model}

To formulate and solve the described problem, we propose a twostage stochastic mixed-integer programming model where uncertainties in the input data will be facilitated in the form of scenario realizations. In two-stage stochastic programs, first stage decisions, represented by $\mathrm{x}$, are taken before some random events are realized. After the realization of uncertainties, second stage actions, y, are taken. In the standard form, $E_{\omega}$ is the expectation and $\omega$ denotes a scenario. A scenario based the two-stage stochastic program can be written as follows:

$$
\begin{array}{ll}
\min & c^{T} x+E_{\omega} Q(x, \omega) \\
& \\
\text { st. } \quad & A x=b \\
& x \geqslant 0
\end{array}
$$

where $Q(x, \omega)=\min \left\{d_{\omega}^{T} y \mid T_{\omega} x+W_{\omega} y=h_{\omega}, y \geqslant 0\right\}$

Tables 1-3 summarize the indices, parameters and variables that we use in our two-stage stochastic mixed integer programming model.

Given the parameters and the variables, the extensive form of our two-stage stochastic programming model is provided as follows:

$$
\begin{aligned}
& \min d_{h} \sum_{i} C_{S i}\left(\operatorname{SUmax}_{i}+\operatorname{SLmax}_{i}\right)+d_{h} \sum_{i} \mathrm{C}_{P G i} P \operatorname{Gmax}_{i}+d_{s} \sum \mathrm{C}_{M j} M_{j} \\
& +d_{t} \sum_{i} \sum_{j} \mathrm{C}_{T i j} \operatorname{Tmax}_{i j}+\sum_{j t \omega} p_{\omega} . Z_{j}^{\omega t} \mu_{\mathrm{j}} \mathrm{n}
\end{aligned}
$$

subject to:

$S U_{i}^{\omega t} \leqslant \operatorname{SUmax}_{i} \quad \forall i, t, \omega$

Table 1

Indices for parameters and decision variables.

\begin{tabular}{ll}
\hline$i:$ & hydropower generation point $1, \ldots, \mathrm{I}$, with a total of I locations \\
$j:$ & demand (solar power generation) point $1, \ldots, \mathrm{J}$, with a total of $\mathrm{J}$ points \\
$t:$ & time period $1, \ldots, \mathrm{T}$, with a total of T periods \\
$\omega:$ & scenarios $1, \ldots, \Omega$, with a total of $\Omega$ scenarios \\
\hline
\end{tabular}


Table 2

Parameters for model.

\begin{tabular}{ll}
\hline$n:$ & length of time periods \\
$d_{h}:$ & dimensionless annualization parameter for hydropower stations \\
$d_{s}:$ & dimensionless annualization parameter for solar power stations \\
$d_{t}:$ & dimensionless annualization parameter for transmission lines \\
$l:$ & percentage power loss in transmission lines \\
$g:$ & acceleration \\
$h_{i}:$ & height of the reservoir in hydropower generation point $\mathrm{i}$ \\
$\alpha:$ & one-way efficiency of hydropower stations both in generating and \\
& pumping mode \\
$\gamma_{S:}:$ & efficiency of solar panels \\
$C_{P G i}:$ & unit cost of reservoir capacity in hydropower generation point $\mathrm{i}$ \\
$C_{M j}:$ & unit cost of pump/generator capacity in hydropower generation point $\mathrm{i}$ \\
$C_{T i j}:$ & unit cost of transmission line capacity between hydropower generation \\
$\mu_{j}:$ & point $\mathrm{i}$ and demand point $\mathrm{j}$ \\
& unit cost of generating electricity using diesel generator (i.e. penalty for \\
$p_{\omega}:$ & mismatched demand in demand point $\mathrm{j}$ ) \\
$\mathrm{M}:$ & weight of scenario $\omega$, where $\sum_{\omega=1}^{\Omega} \mathrm{p}_{\omega}=1$ and $\mathrm{p}_{\omega} \geqslant 0$ \\
& a large number
\end{tabular}

Table 3

Variables of the model.

Exogenous variables:

\begin{tabular}{ll}
\hline$W_{i}^{\omega t}:$ & water runoff to hydropower generation point $\mathrm{i}$ in period $\mathrm{t}$ in scenario $\omega$ \\
$N_{j}^{\omega t}:$ & solar radiation in point $\mathrm{j}$ in period $\mathrm{t}$ in in scenario $\omega$ \\
$D_{j}^{\omega t}:$ & demand in point $\mathrm{j}$ at time $\mathrm{t}$ in in scenario $\omega$
\end{tabular}

State/Decision variables:

\begin{tabular}{|c|c|}
\hline$S U_{i}^{\omega t}:$ & $\begin{array}{l}\text { water stored in the upper reservoir in hydropower generation point } i \text { at } \\
\text { the end of period } t \text { in scenario } \omega\end{array}$ \\
\hline$S L_{i}^{\omega t}:$ & $\begin{array}{l}\text { water stored in the lower reservoir in hydropower generation point } i \text { at } \\
\text { the end of period } t \text { in scenario } \omega\end{array}$ \\
\hline$Z_{j}^{\omega t}:$ & mismatched demand in demand point $\mathrm{j}$ in period $\mathrm{t}$ in scenario $\omega$ \\
\hline$T s d_{i j}^{\omega t}:$ & $\begin{array}{l}\text { electricity sent from hydropower generation point } i \text { to demand point } j \\
\text { in period } t \text { in scenario } \omega\end{array}$ \\
\hline$T d s_{j i}^{\omega t}:$ & $\begin{array}{l}\text { electricity sent from demand point } \mathrm{j} \text { to hydropower generation point } \mathrm{i} \\
\text { in period } t \text { in scenario } \omega\end{array}$ \\
\hline$L U_{i}^{\omega t}:$ & $\begin{array}{l}\text { water spilled from upper reservoir in hydropower generation point } i \text { in } \\
\text { period } t \text { in scenario } \omega\end{array}$ \\
\hline$L L_{i}^{\omega t}:$ & $\begin{array}{l}\text { water spilled from lower reservoir in hydropower generation point } i \text { in } \\
\text { period } t \text { in scenario } \omega\end{array}$ \\
\hline$V_{j}^{\omega t}$ & solar energy internally used in point $\mathrm{j}$ in period $\mathrm{t}$ in scenario $\omega$ \\
\hline$R_{i}^{\omega t}$ : & $\begin{array}{l}\text { water released from upper reservoir in hydropower generation point } \mathrm{i} \\
\text { in period } \mathrm{t} \text { in scenario } \omega\end{array}$ \\
\hline$P_{i}^{\omega t}:$ & $\begin{array}{l}\text { water pumped from lower reservoir to upper reservoir in hydropower } \\
\text { generation point } i \text { in period } t \text { in scenario } \omega\end{array}$ \\
\hline SUmax & active upper reservoir capacity in hydropower generation point $\mathrm{i}$ \\
\hline$S L \max :$ & lower reservoir capacity in hydropower generation point $\mathrm{i}$ \\
\hline$M_{j}$ : & size of solar panels at demand point $\mathrm{j}$ \\
\hline PGmax & generator size in hydropower generation point $\mathrm{i}$ \\
\hline $\operatorname{Tmax}_{i j}$ : & $\begin{array}{l}\text { maximum energy transmitted from hydropower generation point } i \text { to } \\
\text { demand point } \mathrm{j}\end{array}$ \\
\hline$I p_{i}^{\omega t}:$ & $\begin{array}{l}1 \text { if pumping is in operation in hydropower generation point } i \text { in period } \\
t \text { in scenario } \omega, 0 \text { otherwise }\end{array}$ \\
\hline$I s d_{i j}^{\omega t}:$ & $\begin{array}{l}1 \text { if electricity sent from hydropower generation point } \mathrm{i} \text { to demand } \\
\text { point } \mathrm{j} \text { in period } \mathrm{t} \text { in scenario } \omega, 0 \text { otherwise }\end{array}$ \\
\hline
\end{tabular}

$S L_{i}^{\omega t} \leqslant S L \max i \quad \forall i, t, \omega$

$S U_{i}^{\omega t}=S U_{i}^{\omega(t-1)}+W_{i}^{\omega t}+P_{i}^{\omega t}-R_{i}^{\omega t}-L U_{i}^{\omega t} \quad \forall i, t: t>1, \omega$

$S U_{i}^{\omega 1}=S U \max _{i}+W_{i}^{\omega 1}+P_{i}^{\omega 1}-R_{i}^{\omega 1}-L U_{i}^{\omega 1} \quad \forall i, \omega$

$S U_{i}^{\omega T}=S_{\max } \quad \forall i, \omega$

$S L_{i}^{\omega t}=S L_{i}^{\omega(t-1)}+R_{i}^{\omega t}-P_{i}^{\omega t}-L L_{i}^{\omega t} \quad \forall i, t, \omega$

$$
\begin{aligned}
& S L_{i}^{\omega 1}=R_{i}^{\omega 1}-P_{i}^{\omega 1}-L L_{i}^{\omega 1} \quad \forall i, t: t>1, \omega \\
& \max \left\{f_{G i}\left(R_{i}^{\omega t}\right), f_{P i}\left(P_{i}^{\omega t}\right)\right\} \leqslant P G \max _{i} n \quad \forall i, t, \omega \\
& \sum_{j} T s d_{i j}^{\omega t}=f_{G i}\left(R_{i}^{\omega t}\right) \quad \forall i, t, \omega \\
& f_{P i}\left(P_{i}^{\omega t}\right)=\sum_{j} T d s_{j i}^{\omega t}(1-l) \quad \forall \quad \forall i, t, \omega \\
& \max \left\{T s d_{i j}^{\omega t}, T d s_{j i}^{\omega t}\right\} \leqslant \operatorname{Tmax}_{i j} n \quad \forall i, j, t, \omega \\
& V_{j}^{\omega t}+\sum_{i} T d s_{j i}^{\omega t} \leqslant f_{S j}\left(M_{j}\right) \quad \forall j, t, \omega \\
& Z_{j}^{\omega t}=D_{j}^{\omega t}-V_{j}^{\omega t}-\sum_{i} T s d_{i j}^{\omega t}(1-l) \quad \forall j, t, \omega \\
& P_{i}^{\omega t} \leqslant I p_{i}^{\omega t} M \quad \forall i, t, \omega \\
& R_{i}^{\omega t} \leqslant\left(1-I p_{i}^{\omega t}\right) M \quad \forall i, t, \omega \\
& L U_{i}^{\omega t} \leqslant\left(1-I p_{i}^{\omega t}\right) M \quad \forall i, t, \omega \\
& T s d_{i j}^{\omega t} \leqslant I s d_{i j}^{\omega t} M \quad \forall i, j, t, \omega \\
& T d s_{j i}^{\omega t} \leqslant\left(1-I s d_{i j}^{\omega t}\right) M \quad \forall i, j, t, \omega \\
& S U_{i}^{\omega t}, S L_{i}^{\omega t}, S U \max _{i}, S L \max _{i}, P G \max _{i}, P_{i}^{\omega t}, R_{i}^{\omega t}, L U_{i}^{\omega t}, L L_{i}^{\omega t}, M_{j} \text {, } \\
& T_{i j}^{\omega t}, T_{j i}^{\omega t}, \operatorname{Tmax}_{i j}, V_{j}^{\omega t}, Z_{j}^{\omega t} \geqslant 0 \quad \forall i, j, t, \omega \\
& I p_{i}^{\omega t} \in\{0,1\}, I s d_{i j}^{\omega t} \in\{0,1\} \quad \forall i, j, t, \omega
\end{aligned}
$$

The objective of the model in (0) is to minimize the sum of the annualized investment costs and expected total cost of diesel used throughout the year (or expected penalty cost for the mismatched demand). Unit costs of investments are assumed to be the constant incremental amount of installing capacities and indexed by the location so that different costs parameters can be used for different locations. In the model, investment sizing decisions related to system components are the first stage decision variables and operational decisions with $\omega$ index represent the second stage variables. Since we optimize both first stage and second stage decisions over one year planning horizon, the investment costs of the components are discounted with the following annualization parameter:

$d_{s}=i /(1-(1+i)-L T)$

where the lifetime of the system type $s$ and the interest rate are denoted by $L T$ and $i$, respectively.The constraints in (1) and (2) ensure that water stored in the reservoirs is limited by the size of the reservoir for each scenario at all time periods. Constraints in (3)-(5) represent the mass balance equations of water in the reservoirs. The constraint in (3) couples the upper reservoir levels between subsequent time periods. In (4) and (5), we set the initial and final volumes of water in the reservoirs, assuming that upper reservoir begin and end full. In the model, each scenario starts in September, the end of Monsoon season in India, and continues for a year. Thus, it is quite reasonable to assume that reservoirs are full at this time of the year. Constraints in (6) and (7) couple the lower reservoir levels between subsequent time periods. The constraint in (8) ensures that generated and pumped energy are limited by the generator/pump capacity for each scenario at all time periods. These $f_{G i}\left(R_{i}^{\omega t}\right)$ and $f_{P i}\left(P_{i}^{\omega t}\right)$ functions are defined as follows:

$f_{G i}\left(R_{i}^{\omega t}\right)=R_{i}^{\omega t} g h_{i} \alpha$

$f_{P i}\left(P_{i}^{\omega t}\right)=P_{i}^{\omega t} g h_{i} / \alpha$

The constraint in (8) can easily be linearized by substituting the following inequalities:

$f_{G i}\left(R_{i}^{\omega t}\right) \leqslant P G \max i n$ 
$f_{P i}\left(P_{i}^{\omega t}\right) \leqslant P G \max _{i} n$.

The constraint in (9) ensures that in each scenario, energy transmitted to the demand points is equal to energy generated at the hydropower station at each time period. Likewise, (10) provides that pumped energy cannot be greater than the total amount of energy sent from the demand points, and (11) ensures that transmitted energy is limited by the transmission line capacity. In a pumped hydro system, where there is also power flow from demand points, transmission lines are bi-directional and should be sized to accommodate flow in both directions. The constraint in (12) ensures that the sum of the solar energy internally used at a demand point $\mathrm{j}$ and the total energy sent from point $\mathrm{j}$ to hydropower stations is less than or equal to the amount of solar energy generated at that demand point. Energy generated in solar power stations is defined by the function $f_{S j}\left(M_{j}\right)$, which is defined as follows:

$f_{S j}\left(M_{j}\right)=N_{j}^{\omega t} M_{j} \gamma$

The constraint in (13) ensures that demand at point $\mathrm{j}, D_{j}^{\omega t}$ is met by the sum of the energy transmitted from hydropower generation points, solar energy internally used at the demand point and energy produced by burning diesel at the demand point $\mathrm{j}$.

It is observed that the model could result with alternative optimal solutions, some of which may not be desirable from the operational perspective. Binary variables and constraints (14)-(18) are added to the model to prevent such results. For example, without constraints (14), (15) pump and release operations could be observed at the same time period as there is no operational cost related to these operations. Likewise, without constraint (16), water could be simultaneously pumped to and spilled from the upper reservoir. Finally, constraints (17) and (18) provide that the bi-directional transmission lines are only transmitting power in one direction at a given time period.

Furthermore, since for one scenario the policy is "anticipatory" of what is happening in the future, the system spills the water that would not be needed. Although it would also have been optimal to keep water as much as possible in the upper reservoir, the solver can choose the solution with less water. For this reason, in the objective function we may add another term: $\sum_{i t \omega} L U_{i}^{\omega t} \varepsilon$ where $\varepsilon$ is very small. This term tilts the balance so that the solver will choose the option with more water in the upper reservoir. When we report the final cost, we omit this term.

\section{Computational analysis}

The two-stage mixed integer stochastic programming model provided in Section 3 can be easily linearized and solved by a linear programing solver. We use IBM ILOG CPLEX Optimization Studio (CPLEX) [30] to solve it. We present the results of our model using multiple cases from India. We identified Bhagirathi and Chenab Rivers in the Himalaya Mountains as potential hydropower generation areas and Delhi and Punjab states as demand points as shown in Fig. 2. In this section, we first present the input data and parameters used in the computational study. In Section 4.2, we focus on an isolated system that includes one basin (Bhagirathi) and one demand point (Delhi) and run our model with one scenario to understand the systems' dynamics. In Section 4.3 , we examine the benefit of pumped hydro storage at various system scales, comparing the results of the pumped hydro system with a conventional hydro system for two isolated cases with different streamflow potentials. In Section 4.4 we present the results for an integrated system that includes both basins and both demand points.

\subsection{Input data and parameters}

The 3-hourly stream flow data for the basins of Chenab and Bhagirathi Rives for the years between 1951 and 2003 is obtained from a large-scale hydrological land surface model called Variable Infiltration Capacity (VIC) $[31,32]$. The details of this process can be found in [20]. As the problem size quickly rises with the number of scenarios used in the model, we determine 13 years with a variety of streamflow averages to use as different scenarios for analysis throughout the paper.

In India, the normal onset of Monsoon is expected to be observed around June and its withdrawal completes by around October every year. As observed from the streamflow time series data of Bhagirathi River for the years 2000-2002 in Fig. 3a, there is significant seasonal and inter-annual variation. There is also a substantial contribution from snowmelt runoff to the annual streamflow of the Himalayan Rivers $[33,34]$. Most of the snow melts occur in the summer period, correlated with greater periods of sun light and expressed as a diurnal variation in the stream flow (see Fig. 3b). The water yield from a high Himalayan basin is roughly twice that from an equivalent basin located in the peninsular part of India.

Demand profiles of Delhi and Punjab states are obtained from the websites of the Central Electricity Authority, the Power Ministry of India (CEA) and the Load Dispatch Centers [35]. We estimate the 3hourly load profiles for one year using interpolation/extrapolation techniques. The final data can be obtained from [4].

Site and time-specific global and direct irradiance data at hourly intervals on a 10-km grid covering India is available on NREL's website [36]. A 3-hourly solar radiation profile for one year is generated by aggregating hourly radiation data. The solar radiation and demand profiles used in the analysis are presented in Fig. 4.

The cost parameters used in this analysis are obtained from [20] and presented in Table 4 for ease of reference. Transmission costs are estimated using the distances presented in Fig. 2, with the cost parameters given in [4] ( $\$ 0.8 \mathrm{M} / \mathrm{GW} \mathrm{km}$ for the distances between $500 \mathrm{~km}$ and $1000 \mathrm{~km}$ and $\$ 0.8 \mathrm{M} / \mathrm{GW} \mathrm{km}$ for the distances less than $500 \mathrm{~km}$ ).

\subsection{Deterministic analysis of the pumped hydro storage system}

To understand the characteristics of the system and show the benefit of a pumped hydro storage, we first take a deterministic approach where we simply run our model with one scenario for a single basin (Bhagirathi) and single demand point (Delhi) case, which we refer to as the "BD case." For this analysis, the demand data for Delhi presented in Fig. $4 \mathrm{c}$ is normalized to $1 \mathrm{GW}_{\text {peak. }}$. A sample year with $11.46 \mathrm{~km}^{3}$ annual streamflow is used as a scenario.

Fig. 5 shows the water level stored in the upper and lower reservoirs during operation for one year. We start and end the operations at the end of the Monsoon season with full upper reservoirs. The fluctuations in the upper and lower reservoirs represent the pumped hydro operations. There is almost no water stored in the lower reservoir in the Monsoon season since there is no need to pump water to the upper reservoir. We can also observe that the volume of water stored in the lower reservoir (water to be pumped with the extra solar power) during the winter season closely follows the solar radiation curve (Fig.4a). During the dry season (between November and February), the upper reservoir is highly utilized: since the model anticipates the rainy season approaching (violating nonanticipativity condition), it starts utilizing the water stored in the upper reservoir in February. In addition, as there is also high solar radiation in the spring and summer months that can be used to pump water, we observe that there is more water in the lower reservoir until Monsoon seasons starts again. This observation is 


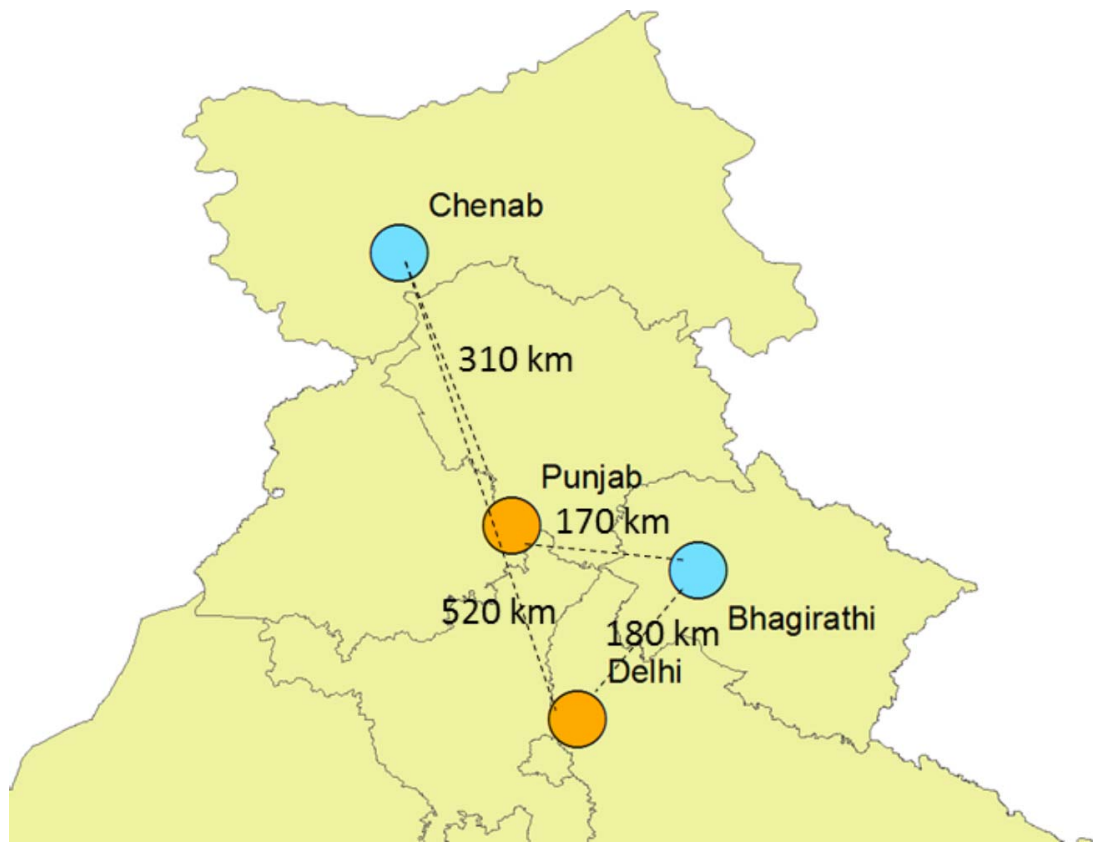

Fig. 2. Demand points and basins used in the case studies.
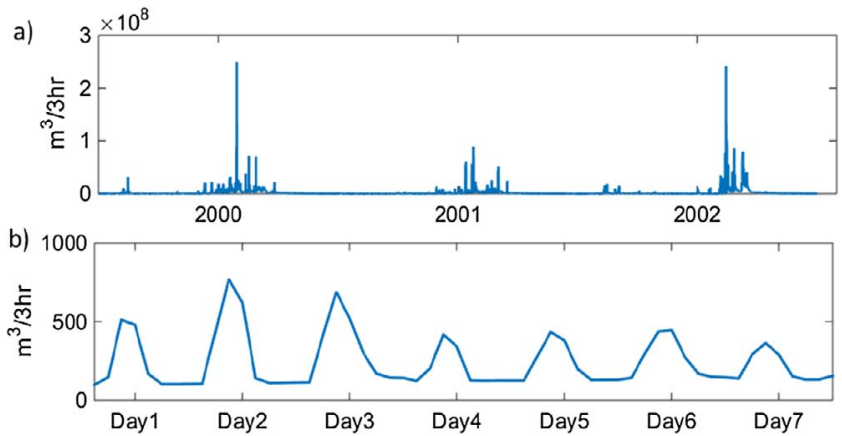

Fig. 3. (a) Stream Flow Data of Bhagirathi River for 2000, 2001 and 2002. Monsoon is expected to be observed around June and its withdrawal completes around October every year. (b) Stream Flow Data of Bhagirathi River for a week in March. Most of the snowmelts occur in the summer period, causing a diurnal variation in the stream flow.

verified by components of the mass balance equations of the upper reservoir, presented in Fig. 6 . In the spring-summer period, the amount of water pumped to the upper reservoir is limited by the generator size, as understood from the flatness of the pumping curve between February and June.

Fig. 7 shows the operations in detail for one week in June. On the second and third days, high water inflow and limited solar radiation
Table 4

Parameters used in the analysis.

\begin{tabular}{lll}
\hline Unit cost of reservoir capacity, $C_{S i}$ & $\$ 3 / \mathrm{m}^{3}$ & $\forall \mathrm{i}$ \\
Unit cost of generator/pump capacity, $C_{P G i}$ & $\$ 500 / \mathrm{kW}$ & $\forall \mathrm{i}$ \\
Unit cost of solar array, $C_{M j}$ & $\$ 200 / \mathrm{m}^{2}$ & $\forall \mathrm{j}$ \\
Unit cost of diesel, $\mu_{j}$ & $\$ 0.25 / \mathrm{kWh}$ & $\forall \mathrm{j}$ \\
Lifetime of the hydropower system: & 60 years & $\forall \mathrm{i}$ \\
Lifetime of the solar power system: & 30 years & $\forall \mathrm{j}$ \\
Lifetime of the transmission system: & 40 years & $\forall \mathrm{jj}$ \\
Efficiency of hydropower system, & $88 \%$ & \\
Efficiency of solar panels, $\gamma$ & $12 \%$ & \\
Discount rate: & $5 \%$ & \\
Power loss in transmission lines: & $5 \%$ & \\
\end{tabular}

amounts eliminate the need for pump operation. In the following days, solar energy meets the daytime demand and hydro satisfies demand at night. Together, these satisfy the demand for the week without a need for any diesel.

Table 5 compares the results of the pumped hydro storage system with the conventional hydro storage system. The additional lower reservoir increases the total hydro production from $24 \%$ to $51 \%$ of demand, allows for a decrease in the size of the upper reservoir compared to the conventional system. The flexibility created by the pumped hydro system facilitates doubling the gross area of solar panel from $12.8 \mathrm{~km}^{2}$
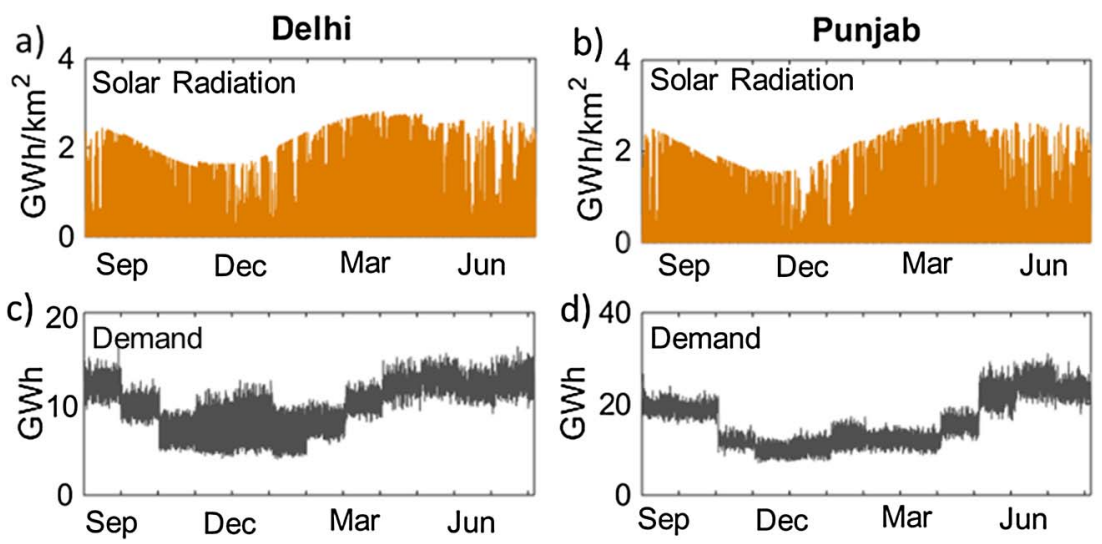

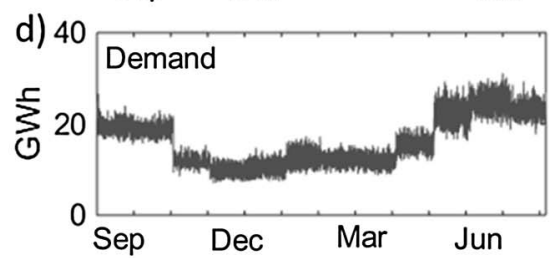

Fig. 4. (a-b) 3-h data of solar radiation per square kilometer for the year 2002 in Delhi and Punjab. (c-d) Estimated demand load curves for one year in Delhi and Punjab, respectively. 


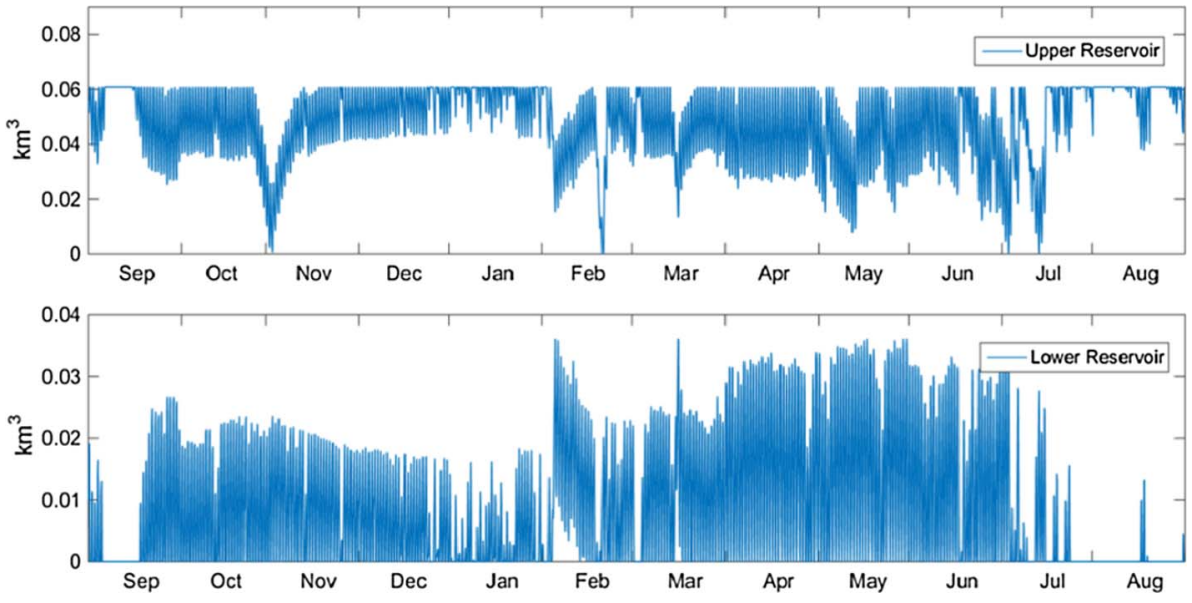

Fig. 5. Water stored in the upper and lower reservoirs - the upper reservoir is assumed to be full at the start and the end of the cycle. There is almost no water stored in the lower reservoir in the Monsoon season since the natural inflow of water eliminates the need to pump water to the upper reservoir. $\left(0.01 \mathrm{~km}^{3} \sim 2.4 \mathrm{GWh}\right)$. to $24.7 \mathrm{~km}^{2}$. The amount of diesel required to meet the demand is reduced from $38 \%$ to $6 \%$ and the unit cost of the system is reduced from $13.4 \mathrm{~d} / \mathrm{kWh}$ to $8.6 \mathrm{\phi} / \mathrm{kWh}$. We note here that since we meet the same amount of demand at both systems, the revenues that will be obtained from the energy generated in these systems will also be the same. Therefore, profit maximization can be achieved by minimizing the cost of the system. Further details about the production amounts, capacity factors, and unit costs of the system components are summarized below in Table 5.

The detailed distribution of alternative sources to meet the demand is presented in Fig. 8. 22\% of the demand is met by hydropower generated by the natural inflow to the reservoir and $29 \%$ is generated using pumped water. Solar panels generate $80 \%$ of the annual demand, where $43 \%$ is used directly as "internal" solar energy and $37 \%$ is sent to reservoirs to be stored. The $8 \%$ difference between the hydro energy generated from the pumped water and solar energy sent to reservoirs stems from the generator and pump inefficiencies.

Another interesting result demonstrated in Table 5 and Fig. 8 is the higher amount of internally used solar energy in the pumped hydro system compared to the conventional system. This is mainly due to the fact that it is expected that solar panel area in pumped hydro system is larger than the area in the conventional system as the role of solar energy in the pumped system is twofold: internal solar and pumped solar. In addition, in the pumped hydro system, solar energy is usually transmitted to the hydro stations for pumping for two consecutive time periods (total of $6 \mathrm{~h}$ ) in one day on average. However, solar radiation is available for longer time periods during the day and since the solar panel area is larger, the energy generated during the day when there is no pumping can also be used internally. Therefore, increased solar panel area also contributes the internally used solar energy. In particular, in Table 5 , we see $43 \%$ of the demand is met by internally used solar energy in the pumped system, whereas in the conventional system this amount is $38 \%$. Fig. 9 compares conventional and pumped hydro systems in terms of the solar energy produced in one day. It can be seen that total production is scaled up by increased solar panel area, as the solar radiation curve is same. Solar energy used internally for the 4th and 5th 3-hourly time periods are the same, as extra solar energy is spent for pumping; however, difference in the 3rd and 6th 3-hourly time periods in Fig. 9 explains why internally used solar energy percentage in the pumped system is higher than the percentage in the conventional system.

In Fig. 9, we also observe that some of the solar energy is spilled or wasted in the afternoon in the 4th and 5th 3-hourly time periods in the conventional system, as solar energy potential is more than the demand at these time periods. With this result, we see that spilling some solar energy may lead to a profitable decision. That is, even though some spilling is allowed during the day, extra solar energy generated in the morning and late afternoon justifies the investment and makes the system result with a lower unit cost. This result also supports the discussion provided in Kocaman et al. for the conventional systems [20]. With this analysis, we show that a similar observation also exists in the pumped system. Solar panel is sized in a way that some solar energy

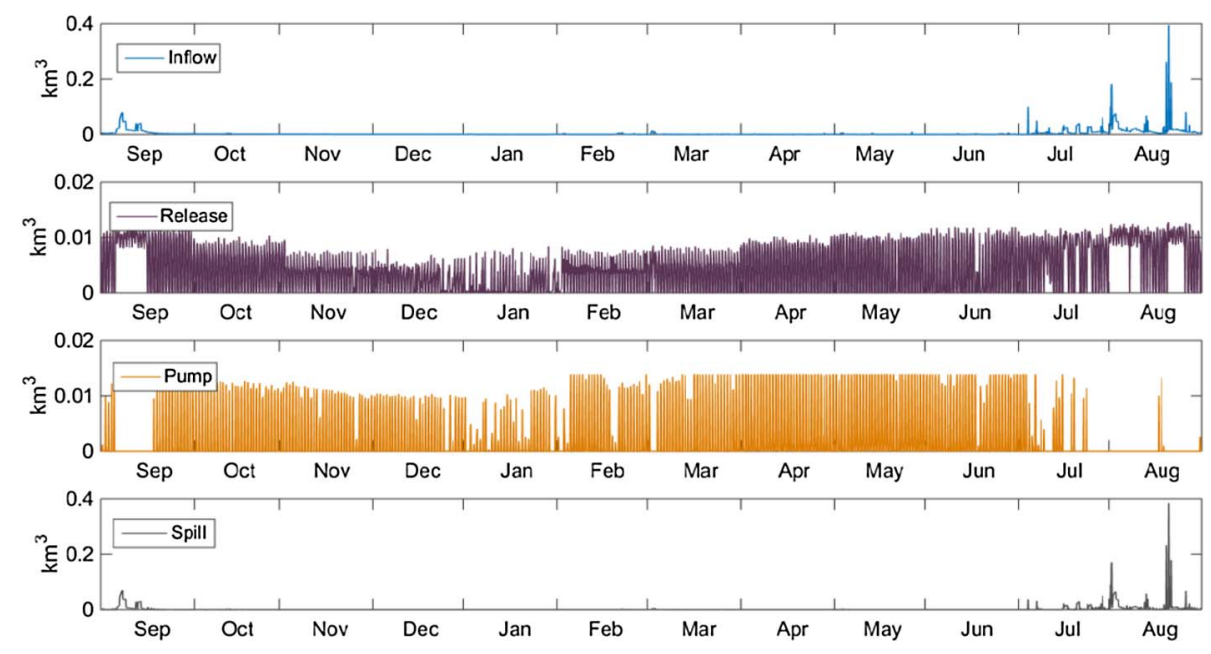

Fig. 6. Flows from/to the upper reservoir - pump operations are limited during the Monsoon season due to high natural inflow into the reservoir. $\left(0.01 \mathrm{~km}^{3} \sim 2.4 \mathrm{GWh}\right)$. 


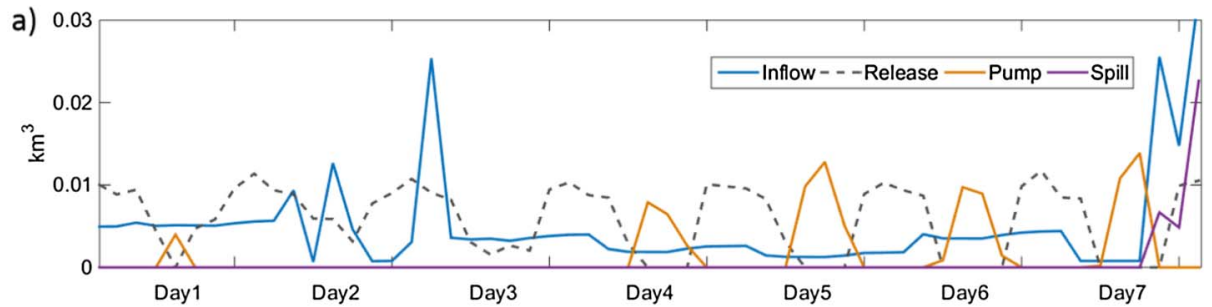

b)

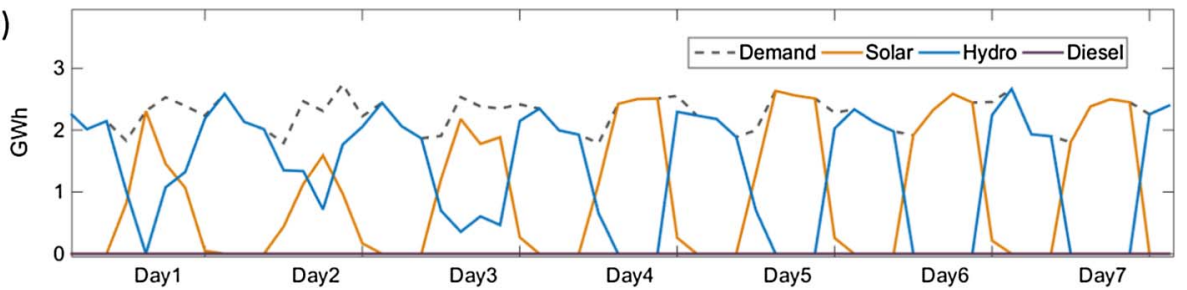

Fig. 7. Operation balance in reservoir and demand points for one week in June. (a) Due to the inflow observed in the second and third day of the week, there is no need for the pump operation. (b) Solar energy meets the demand during the day and hydro becomes effective at night. Diesel usage is zero for the entire week.
Table 5

Results of the pumped hydro system compared to the conventional system.

\begin{tabular}{|c|c|c|c|c|}
\hline & \multicolumn{2}{|c|}{ w/ pumped $\mathrm{H}$. } & \multicolumn{2}{|c|}{ w/ conventional $\mathrm{H}$. } \\
\hline Upper reservoir size $\left(\mathrm{km}^{3}\right)$ & & 0.061 & & 0.080 \\
\hline Lower Reservoir $\left(\mathrm{km}^{3}\right)$ & & 0.036 & & NA \\
\hline Solar Panel Area $\left(\mathrm{km}^{2}\right)$ & & 24.770 & & 12.814 \\
\hline Generator/Pump Capacity (GW) & & 1.431 & & 0.863 \\
\hline Transmission Line (GW) & & 1.506 & & 0.863 \\
\hline \multicolumn{5}{|l|}{ Unit Cost $(\$ / k W h)$} \\
\hline Hydro & & 0.024 & & 0.033 \\
\hline Solar & & 0.071 & & 0.080 \\
\hline Diesel & & 0.250 & & 0.250 \\
\hline System & & 0.086 & & 0.134 \\
\hline \multicolumn{5}{|l|}{ Hydro Production with } \\
\hline Inflow & & 1387 & & 1395 \\
\hline Pumped Water & & 1595 & & NA \\
\hline Total Hydro Production (GWh) & & 2982 & & 1395 \\
\hline \multicolumn{5}{|l|}{ Solar Production } \\
\hline Used Internally & & 2358 & & 2080 \\
\hline Sent to be Pumped & & 2168 & & NA \\
\hline Spilled & & 1025 & & 792 \\
\hline Total Solar Production (GWh) & & 5551 & & 2872 \\
\hline \multicolumn{5}{|l|}{ Energy Distribution (GWh) } \\
\hline Hydro & $51 \%$ & 2833 & $24 \%$ & 1326 \\
\hline Solar & $43 \%$ & 2358 & $38 \%$ & 2080 \\
\hline Diesel & $6 \%$ & 334 & $38 \%$ & 2119 \\
\hline Total & $100 \%$ & 5525 & $100 \%$ & 5525 \\
\hline \multicolumn{5}{|l|}{ Peaks observed for (GW) } \\
\hline Diesel Usage & & 0.82 & & 1.00 \\
\hline Solar Production & & 2.79 & & 1.44 \\
\hline Hydro Production & & 1.05 & & 0.86 \\
\hline Solar Pumped & & 1.43 & & NA \\
\hline \multicolumn{5}{|l|}{ Capacity Factor } \\
\hline Hydro & $\begin{array}{l}0.16 \\
\text { (pump) }\end{array}$ & $\begin{array}{l}0.24 \\
\text { (turbine) }\end{array}$ & & 0.18 \\
\hline Solar & & 0.23 & & 0.23 \\
\hline Transmission & 0.16 (solar) & 0.23 (hydro) & & 0.18 \\
\hline
\end{tabular}

could be spilled in the 5th 3-hourly time period so that internally used and pumped solar energy could be generated more in the other time periods of the day."

\subsection{The benefit of pumped hydro storage at various system scales}

In the previous section, sizing and operations of the pumped storage system to meet $1 \mathrm{GW}_{\text {peak }}$ demand are examined and compared to the conventional hydro system for one scenario. In this section, considering the uncertainty of the streamflow, we provide the results of the pumped storage system to meet the demand at various scales between 0.5 $\mathrm{GW}_{\text {peak }}$ and $5 \mathrm{GW}_{\text {peak. }}$ In addition to Bhagirathi-Delhi (BD) case, we also study Chenab-Punjab (CP) case, which has similar demand and solar radiation profiles (Fig. 4) but seven times more streamflow on average. The detailed result tables of these cases can be found in the Appendix. In Fig. 10, we present the results of the pumped hydro system in comparison with the conventional hydro system for the BD case on the left column and $\mathrm{CP}$ case on the right column. In the pumped hydro systems, both upper and lower reservoir sizes increase as the system demand increases. In the conventional hydro system of BD case, the reservoir size initially increases with demand but plateaus after 2 $\mathrm{GW}_{\text {peak }}$ as the benefit of extra reservoir size is diminished by scarcity of water. In the CP case, however, the hydropower system operates much like a run-of-the-river system for demands scaled to $0.5 \mathrm{GW}_{\text {peak }}$ and 1 $\mathrm{GW}_{\text {peak }}$ because of the high streamflow potential. As the demand is increased further, solar energy becomes critical and a larger reservoir is needed for water storage. Solar panel requirements in the systems are presented in Fig. 10c and d. As expected, a pumped system increases the installable capacity of solar compared to a conventional system.

Fig. 10e and $\mathrm{f}$, shows the distribution of sources needed to meet demand. In the conventional systems, the requirement for diesel rises very quickly for increasing demand scales, whereas in the pumped system the diesel contribution is fixed at $6-7 \%$. The greater need for diesel in the conventional system leads to higher system unit costs, as can be observed in Fig. 10g and h. For systems with lower streamflow potential (as in BD case), the benefit of installing a pumped hydro system is immediately apparent as a reduction in unit cost. For systems with high streamflow potential (as in CP case), pumped hydro garners a reduction in unit cost only when demand surpasses $2 \mathrm{GW}_{\text {peak }}$.

\subsection{The benefit of pumped hydro storage in integrated systems}

With the help of inter-regional transmission lines, energy systems can benefit from geographic diversity and resource sharing. In Kocaman et al. [20], the authors investigate using conventional hydropower to support $1 \mathrm{GW}_{\text {peak }}$ solar generation to meet $1 \mathrm{GW}_{\text {peak }}$ demand for both isolated (BD and $\mathrm{CP}$ cases) and integrated cases and show that the overall cost of the system could be nearly halved by installing two transmission lines to integrate the systems. In this section, we examine the benefit pumped hydro storage offers the integrated systems over conventional hydro storage when co-optimized wit solar generation capacity. In Table 6, we compare the results from isolated cases with the results from an integrated case. In Table 7, the integrated system with pumped hydro storage is compared to an integrated system with conventional hydro storage. We note here that in the model of the integrated system, if the capacities of the transmission lines that connect 


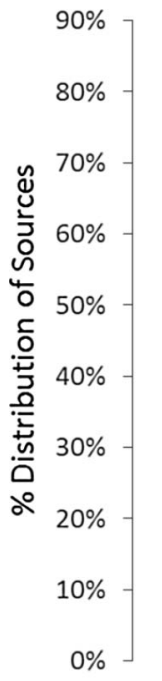

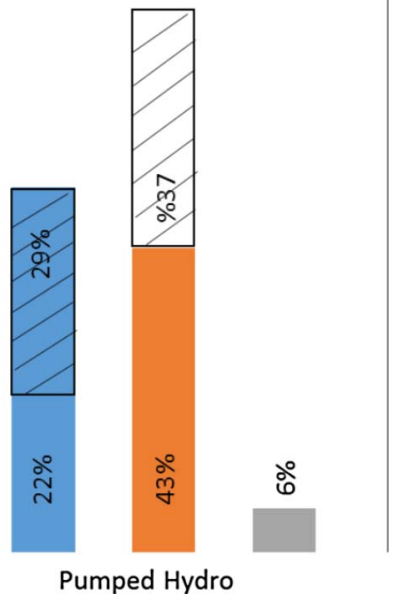

Pumped Hydro
Hydro Solar Diesel

Fig. 8. Percentage distribution of resources to meet the demand Shaded area in the solar power bar is transferred to hydro power. $8 \%$ is lost due to generator and pump efficiencies. the isolated systems are set to zero, we obtain the optimal solution of the isolated cases. Since the additional constraints will make the solution space smaller, we expect that integrated system model always finds at least as good a solution as the model of the isolated sytems.

In Table 6, we present the system sizing, expected energy distribution of the sources, and the expected unit cost of the system for both the integrated system and isolated systems, where the demand at each demand point is scaled to $1 \mathrm{GW}_{\text {peak }}$. We observe that the sizes of all system components -including transmission lines- are reduced significantly in the integrated system (58\% for reservoirs, $34 \%$ for solar panels, $24 \%$ for generator/pump and $22 \%$ for transmission lines). While the additional $1 \%$ of the total demand is met by the energy produced by burning diesel, the total cost of the overall system is decreased by $17 \%$. Furthermore, total solar generation in the integrated system is reduced while the hydro generation due to natural inflow is increased. This result shows us that resource-sharing in integrated systems could substitute for energy storage.

In Table 7 we compare the integrated systems with conventional hydro storage and pumped hydro storage. If the lower reservoir size is fixed to zero in the model of the pumped system, we obtain the optimal solution for the conventional system. Therefore, we expect the system cost with pumped hydro to be always less than or equal to the system cost with conventional hydro. However, Table 7 shows us that the integrated system with conventional hydro is almost as good as the system with pumped hydro. In the pumped system, solar investment is increased while the diesel usage is reduced, but this only leads to a reduction in unit cost from $5 \mathrm{\$} / \mathrm{kWh}$ in the traditional hydro systems to $4.9 \mathrm{~d} / \mathrm{kWh}$ in the pumped hydro system. In some cases like the one here, the required upper reservoir volume of a pumped hydro system is smaller than the reservoir needed for a conventional system. This result suggests that existing conventional hydropower stations could be converted to pumped hydro stations without needing to modify the upper reservoir.

\section{Conclusion}

We presented a two-stage mixed integer stochastic programming model to help infrastructure planners understand the solar radiation and streamflow coherence and determine the optimal capacities of PHES systems for supporting solar generation given realistic cost
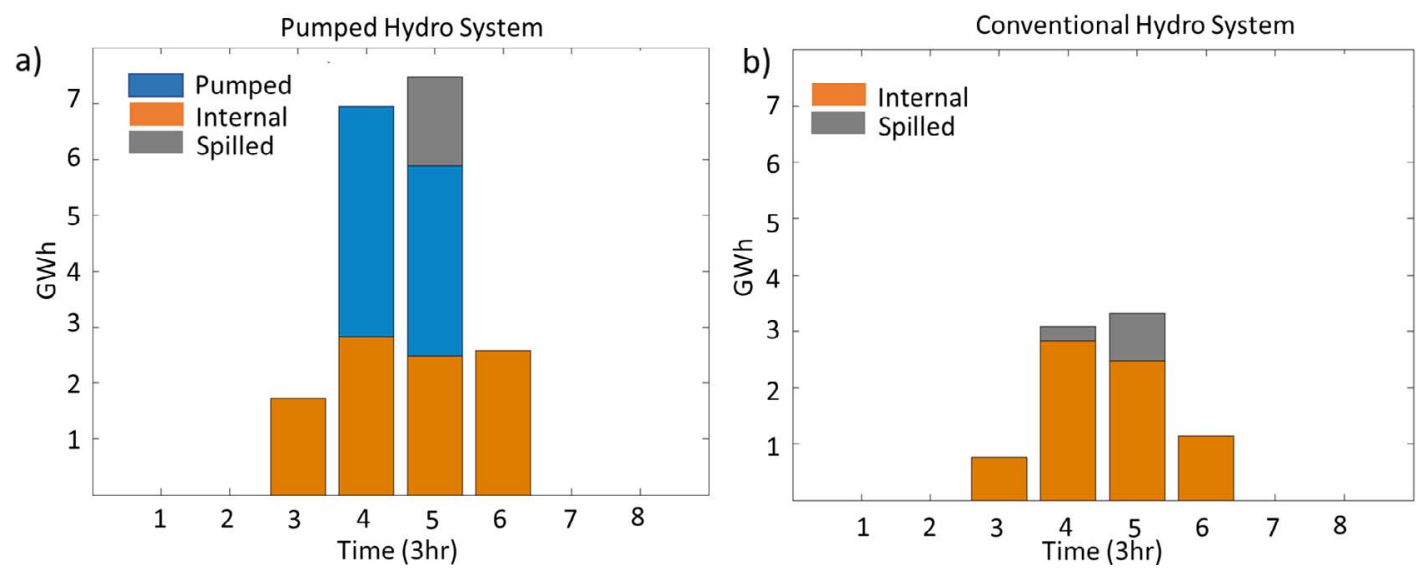

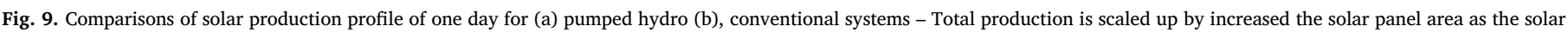

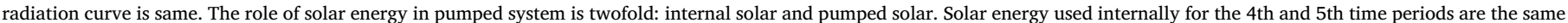
between two systems as extra solar energy is spent for pumping; however, the difference in the 3rd and 6th time periods represents extra solar internal. 

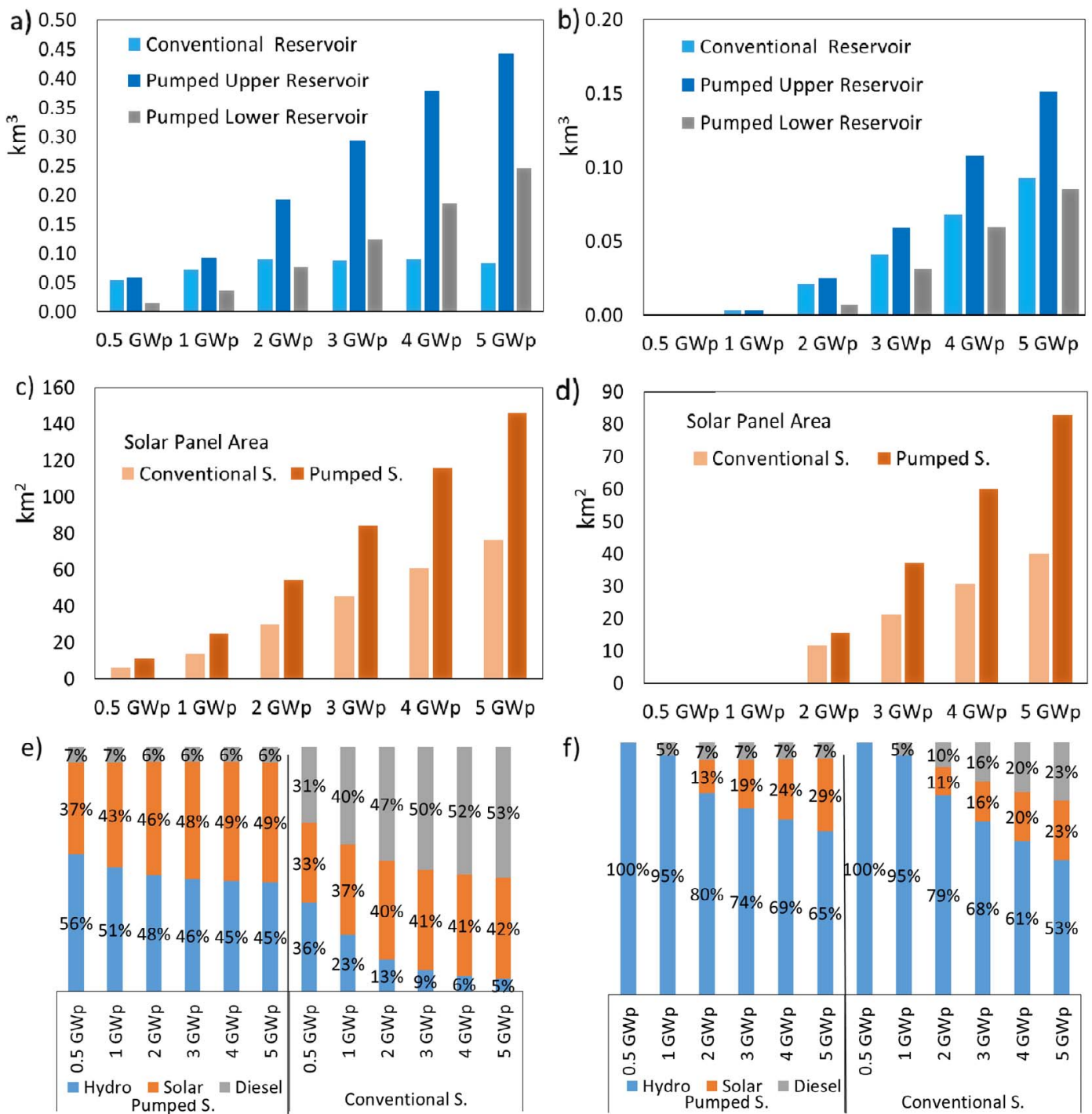

f)
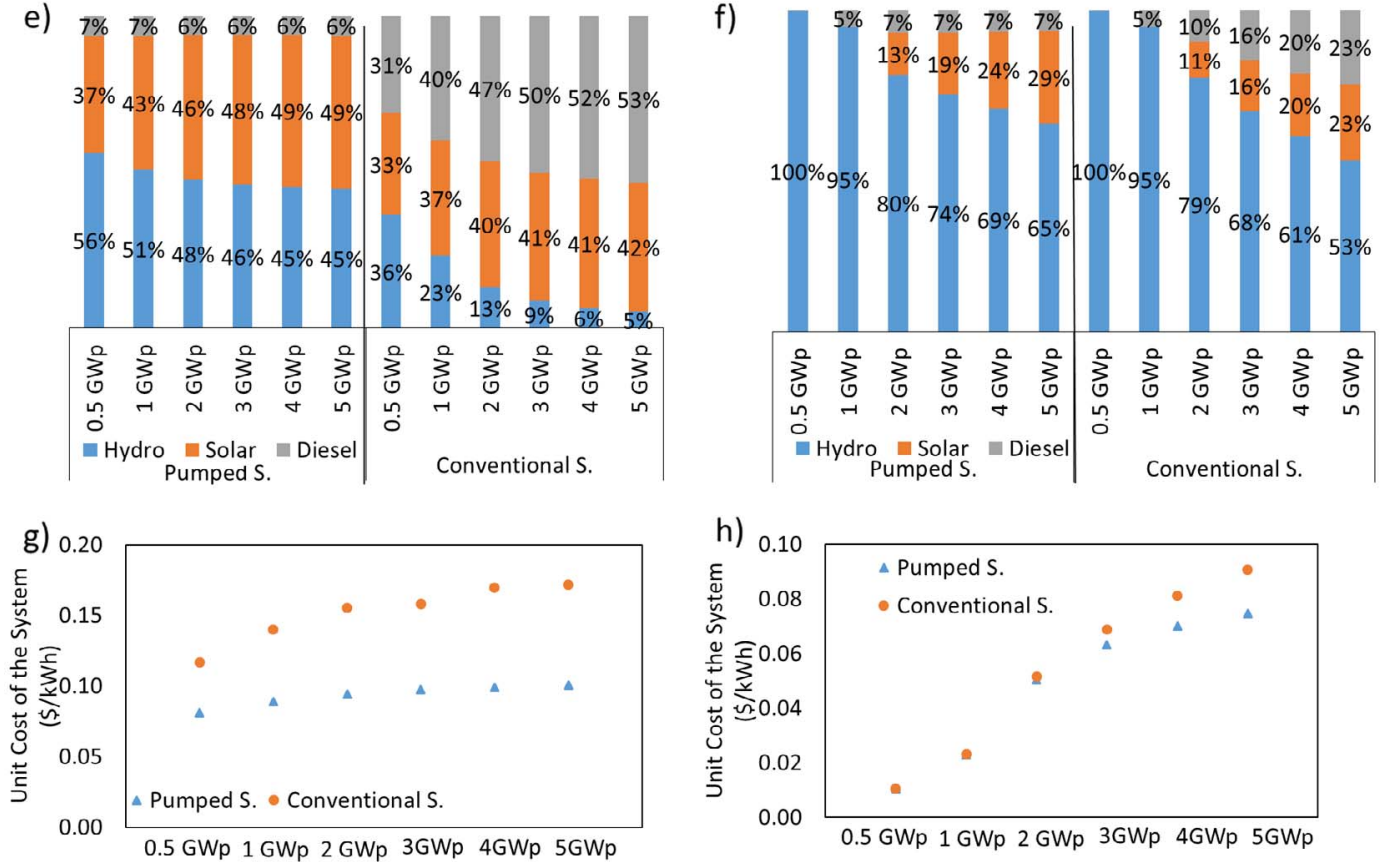

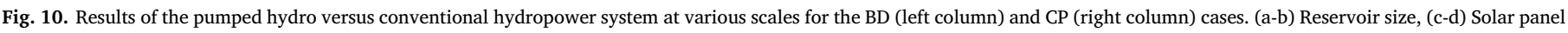
area, (e-f) Percentage distribution of sources to meet the demand, (g-h) System unit cost.

parameters. Co-optimizig a storage system such as PHES with a solar installation can help address solar's intermittency problem, allowing for a greater capacity of solar to be installed on a grid.

In this study, we considered open PHES systems that are fed by natural inflow from a river. As this kind of system can also work as a conventional hydropower station, this model provided us with the opportunity to examine the role a lower reservoir plays at alternative streamflow potentials and demand scales. We used diesel as a proxy for expensive fossil resources and demonstrated that pumped hydro storage can dramatically decrease its need.

We presented that hydropower potential in the Himalaya Mountains is heavily site-dependent and shows significant variability and uncertainty. To examine the benefits of geographic diversification of streamflow potential, we compared the role of PHES in isolated systems and integrated systems, concluding that the contribution of the PHES systems is more significant in isolated cases as resource-sharing serves a 
Table 6

Summarized results for the integrated system versus isolated systems.

\begin{tabular}{|c|c|c|c|c|}
\hline & \multicolumn{2}{|c|}{ Integrated Case w/ Pumped H. } & \multicolumn{2}{|c|}{ Isolated Cases w/ Pumped H. } \\
\hline & Bhagirathi/Delhi & Chenab/Punjab & $\mathrm{BD}$ & $\mathrm{CP}$ \\
\hline $\begin{array}{l}\text { Upper Reservoir Size } \\
\qquad\left(\mathrm{km}^{3}\right)\end{array}$ & 0.025 & 0.018 & 0.091 & 0.003 \\
\hline Lower Reservoir $\left(\mathrm{km}^{3}\right)$ & 0.009 & 0.001 & 0.036 & 0.000 \\
\hline Solar Panel Area $\left(\mathrm{km}^{2}\right)$ & 9.518 & 6.934 & 25.111 & 0.000 \\
\hline $\begin{array}{l}\text { Generator/Pump } \\
\text { Capacity (GW) }\end{array}$ & 0.410 & 1.363 & 1.406 & 0.927 \\
\hline \multirow{2}{*}{$\begin{array}{l}\text { Transmission Line } \\
\text { (GW) }\end{array}$} & 0.303 & 0.222 & 1.480 & 0.927 \\
\hline & 0.634 & 0.729 & - & - \\
\hline \multicolumn{5}{|l|}{$\begin{array}{l}\text { Expected Unit Cost } \\
(\$ / \mathrm{kWh})\end{array}$} \\
\hline Hydro & 0.011 & & 0.026 & 0.010 \\
\hline Solar & 0.122 & & 0.073 & NA \\
\hline Diesel & 0.250 & & 0.250 & 0.250 \\
\hline System & 0.049 & & 0.089 & 0.023 \\
\hline \multicolumn{5}{|l|}{ Expected Energy } \\
\hline Hydro & $77.4 \%$ & & $50.7 \%$ & $94.6 \%$ \\
\hline Solar & $15.0 \%$ & & $42.8 \%$ & $0.0 \%$ \\
\hline Diesel & $7.5 \%$ & & $6.5 \%$ & $5.5 \%$ \\
\hline Total & $100 \%(5525+4585)$ & & $\begin{array}{l}100 \% \\
(5525)\end{array}$ & $\begin{array}{l}100 \% \\
(4585)\end{array}$ \\
\hline
\end{tabular}

Table 7

Summarized results for the integrated systems with pumped hydro storage and conventional hydro storage.

\begin{tabular}{|c|c|c|c|c|}
\hline & \multicolumn{2}{|l|}{ Integrated Pump H. } & \multicolumn{2}{|c|}{ Integrated Conventional $\mathrm{H}$. } \\
\hline & Bhagirathi/Delhi & Chenab/Punjab & Bhagirathi/Delhi & Chenab/Punjab \\
\hline $\begin{array}{l}\text { Upper Reservoir Size } \\
\left(\mathrm{km}^{3}\right)\end{array}$ & 0.025 & 0.018 & 0.035 & 0.021 \\
\hline $\begin{array}{l}\text { Lower Reservoir } \\
\qquad\left(\mathrm{km}^{3}\right)\end{array}$ & 0.009 & 0.001 & NA & NA \\
\hline $\begin{array}{c}\text { Solar Panel Area } \\
\left(\mathrm{km}^{2}\right)\end{array}$ & 9.518 & 6.934 & 8.036 & 5.627 \\
\hline $\begin{array}{l}\text { Generator/Pump } \\
\text { Capacity (GW) }\end{array}$ & 0.410 & 1.363 & 0.243 & 1.546 \\
\hline \multirow{2}{*}{$\begin{array}{l}\text { Transmission Line } \\
\text { (GW) }\end{array}$} & 0.303 & 0.222 & 0.167 & 0.180 \\
\hline & 0.634 & 0.729 & 0.772 & 0.774 \\
\hline \multicolumn{5}{|l|}{$\begin{array}{l}\text { Expected Unit Cost } \\
(\$ / \mathrm{kWh})\end{array}$} \\
\hline Hydro & 0.011 & & 0.011 & \\
\hline Solar & 0.122 & & 0.144 & \\
\hline Diesel & 0.250 & & 0.250 & \\
\hline System & 0.049 & & 0.050 & \\
\hline \multicolumn{5}{|l|}{ Expected Energy } \\
\hline Hydro & $77.4 \%$ & & $78.1 \%$ & \\
\hline Solar & $15.0 \%$ & & $12.6 \%$ & \\
\hline Diesel & $7.5 \%$ & & $9.3 \%$ & \\
\hline Total & $100 \%(5525+4585)$ & & $100 \%(5525+4585)$ & \\
\hline
\end{tabular}

similar purpose of leveling loads in integrated systems.

Another interesting result that we showed is that pumped hydro systems allows for a greater capacity of solar to be installed economically compared to conventional systems. The amount of internally used solar energy within the demand points is higher in the systems with PHES as solar energy meets the morning and late afternoon demands more effectively due to increased solar panel area.

\section{Acknowledgement}

We gratefully acknowledge the insightful comments and suggestions of three anonymous reviewers and the editors, which led to several improvements in our manuscript. We also thank Noah Rauschkolb for helpful discussions. 


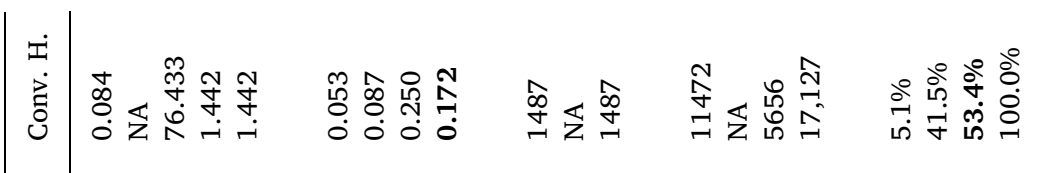

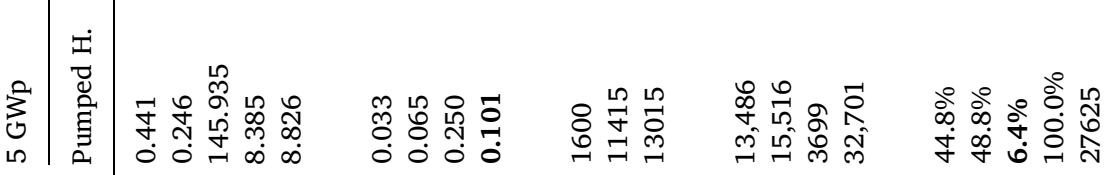

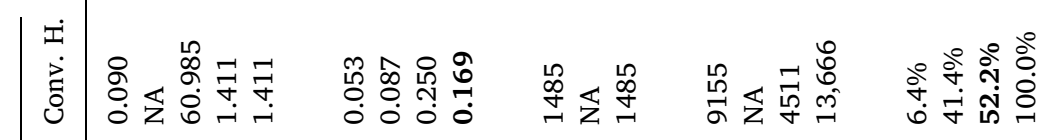

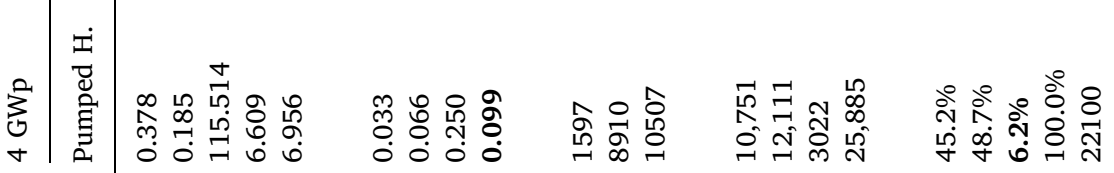

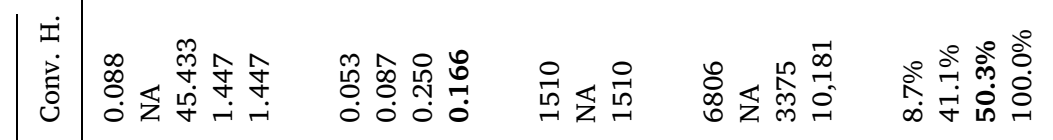

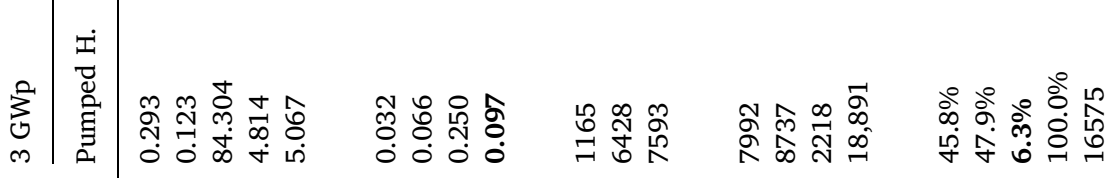

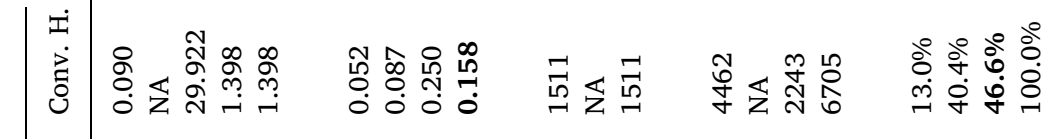

言产

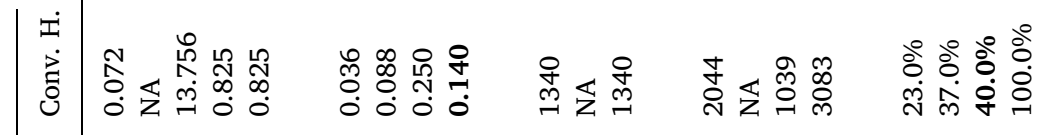

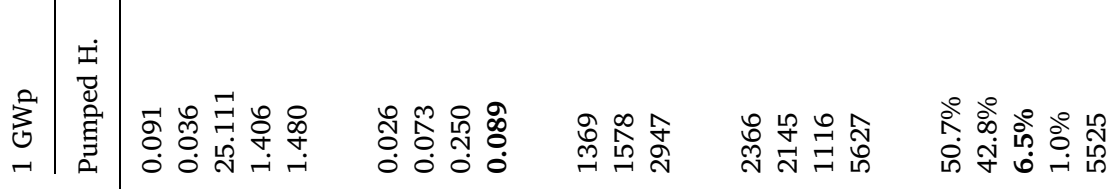

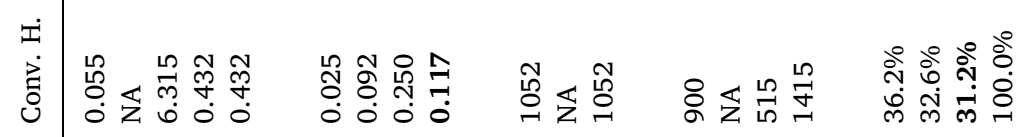

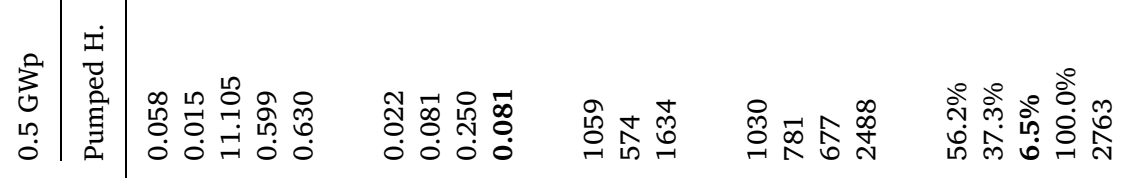
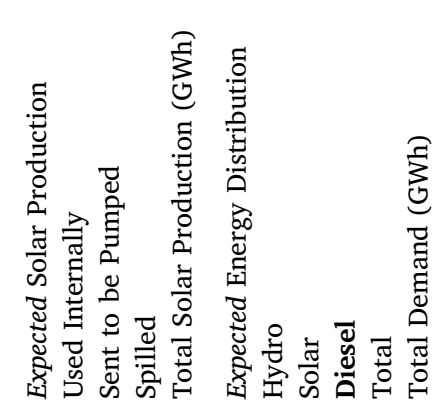

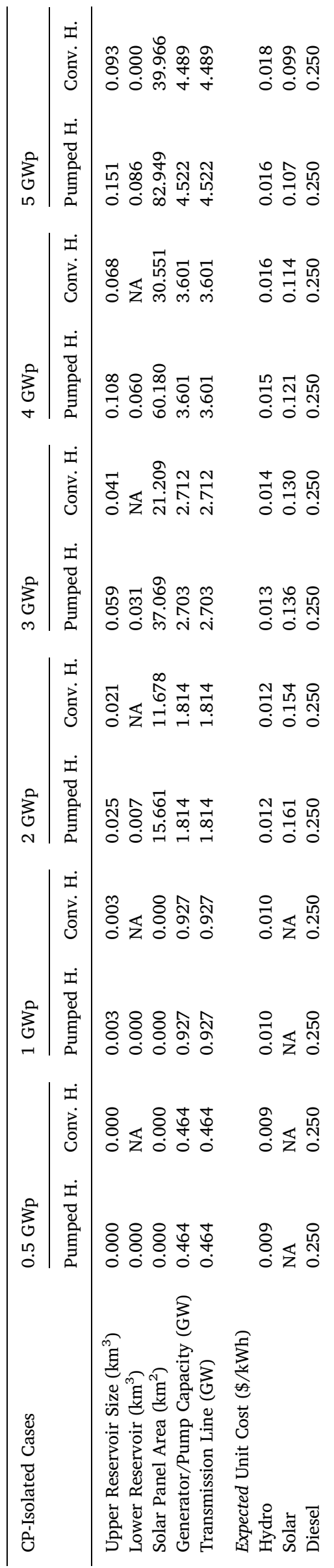




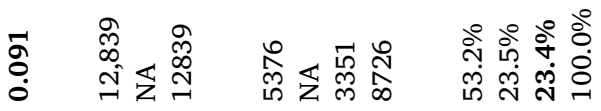

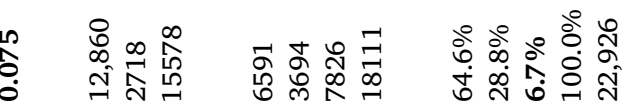

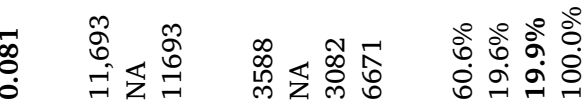

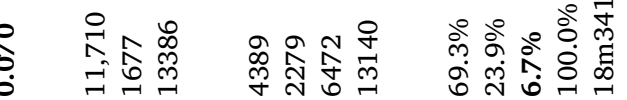

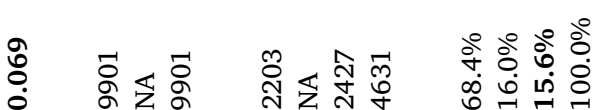

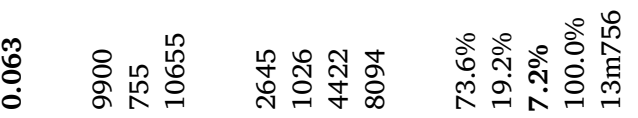

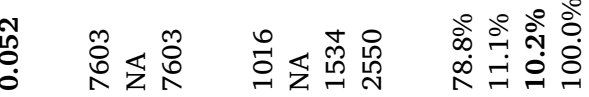

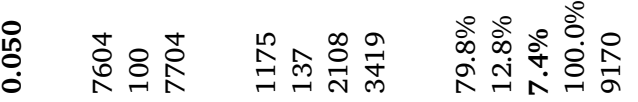

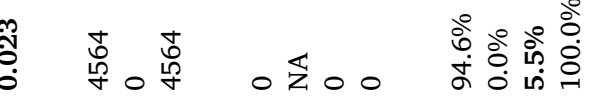

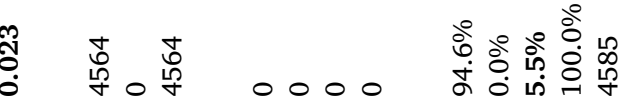

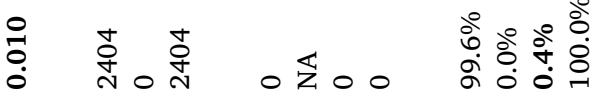

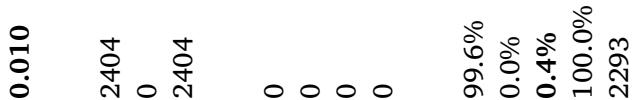

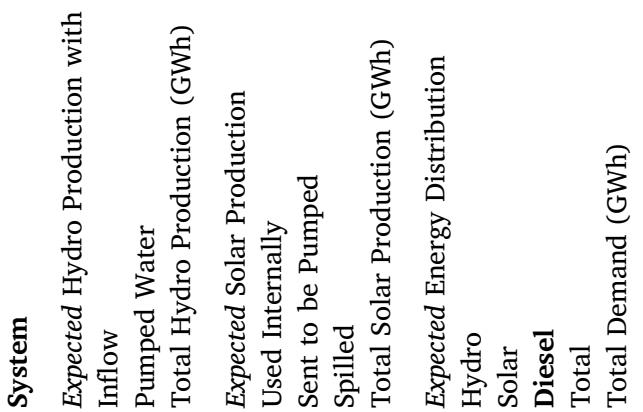

\section{References}

[1] Jacobson MZ, Delucchi MA. Providing all global energy with wind, water, and solar power, Part I: Technologies, energy resources, quantities and areas of infrastructure, and materials. Energy Policy 2011;39(3):1154-69.

[2] Delucchi MA, Jacobson MZ. Providing all global energy with wind, water, and solar power, Part II: Reliability, system and transmission costs, and policies. Energy Policy 2011;39(3):1170-90.

[3] Crabtree G, Misewich J, Ambrosio R, Clay K, DeMartini P, James R, et al. Integrating renewable electricity on the grid. In: AIP Conference proceedings, vol. 1401, No. 1; 2011, November, p. 387-405. AIP.

[4] Kocaman AS. Essays on infrastructure design and planning for clean energy systems. Columbia University; 2014.

[5] Katzenstein W, Fertig E, Apt J. The variability of interconnected wind plants. Energy Policy 2010;38(8):4400-10.

[6] Fertig E, Apt J, Jaramillo P, Katzenstein W. The effect of long-distance interconnection on wind power variability. Environ Res Lett 2012;7(3):034017.

[7] Belfkira R, Zhang L, Barakat G. Optimal sizing study of hybrid wind/PV/diesel power generation unit. Sol Energy 2011;85(1):100-10.

[8] Kaabeche A, Ibtiouen R. Techno-economic optimization of hybrid photovoltaic/ wind/diesel/battery generation in a stand-alone power system. Sol Energy 2014;103:171-82.

[9] Yang H, Wei Z, Chengzhi L. Optimal design and techno-economic analysis of a hybrid solar-wind power generation system. Appl Energy 2009;86(2):163-9.

[10] Zhao B, Zhang X, Li P, Wang K, Xue M, Wang C. Optimal sizing, operating strategy and operational experience of a stand-alone microgrid on Dongfushan Island. Appl Energy 2014;113:1656-66.

[11] González A, Riba JR, Rius A, Puig R. Optimal sizing of a hybrid grid-connected photovoltaic and wind power system. Appl Energy 2015;154:752-62.

[12] Senjyu T, Hayashi D, Yona A, Urasaki N, Funabashi T. Optimal configuration of power generating systems in isolated island with renewable energy. Renew Energy 2007;32(11):1917-33.

[13] Stoyan SJ, Dessouky MM. A Stochastic Mixed-Integer Programming approach to the energy-technology management problem. Comput Ind Eng 2011.

[14] Powell WB, George A, Simão H, Scott W, Lamont A, Stewart J. SMART: A Stochastic Multiscale Model for the Analysis of Energy Resources, Technology, and Policy. INFORMS J Comput 2012;24(4):665-82.

[15] Ekren O, Ekren BY, Ozerdem B. Break-even analysis and size optimization of a PV/ wind hybrid energy conversion system with battery storage-a case study. Appl Energy 2009;86(7):1043-54.

[16] Ekren O, Ekren BY. Size optimization of a PV/wind hybrid energy conversion system with battery storage using simulated annealing. Appl Energy 2010;87(2):592-8.

[17] Roy A, Kedare SB, Bandyopadhyay S. Optimum sizing of wind-battery systems incorporating resource uncertainty. Appl Energy 2010;87(8):2712-27.

[18] Arun P, Banerjee R, Bandyopadhyay S. Optimum sizing of photovoltaic battery systems incorporating uncertainty through design space approach. Sol Energy 2009;83(7):1013-25.

[19] Kuznia L, Zeng B, Centeno G, Miao Z. Stochastic optimization for power system configuration with renewable energy in remote areas. Ann Oper Res 2011:1-22.

[20] Kocaman AS, Abad C, Troy TJ, Huh WT, Modi V. A stochastic model for a macroscale hybrid renewable energy system. Renew Sustain Energy Rev 2016;54:688-703.

[21] Pearre NS, Swan LG. Technoeconomic feasibility of grid storage: mapping electrical services and energy storage technologies. Appl Energy 2015;137:501-10.

[22] Pérez-Díaz JI, Chazarra M, García-González J, Cavazzini G, Stoppato A. Trends and challenges in the operation of pumped-storage hydropower plants. Renew Sustain Energy Rev 2015;44:767-84.

[23] Rehman S, Al-Hadhrami LM, Alam MM. Pumped hydro energy storage system: a technological review. Renew Sustain Energy Rev 2015;44:586-98.

[24] Kapsali M, Anagnostopoulos JS, Kaldellis JK. Wind powered pumped-hydro storage systems for remote islands: a complete sensitivity analysis based on economic perspectives. Appl Energy 2012;99:430-44.

[25] Katsaprakakis DA, Christakis DG, Pavlopoylos K, Stamataki S, Dimitrelou I, Stefanakis I, Spanos P. Introduction of a wind powered pumped storage system in the isolated insular power system of Karpathos-Kasos. Appl Energy 2012;97:38-48.

[26] Brown PD, Lopes JP, Matos MA. Optimization of pumped storage capacity in an isolated power system with large renewable penetration. IEEE Transact Power Syst 2008;23(2):523-31.

[27] Ma T, Yang H, Lu L, Peng J. Pumped storage-based standalone photovoltaic power generation system: Modeling and techno-economic optimization. Appl Energy 2015;137:649-59.

[28] Forsund FR. Hydropower economics, vol. 217. Springer; 2015.

[29] Garcia-Gonzalez J, de la Muela RR, Santos LM, González AM. Stochastic joint optimization of wind generation and pumped-storage units in an electricity market. Power Systems, IEEE Transact 2008;23(2):460-8.

[30] < http://www-01.ibm.com/software/info/ilog/ > [last accessed 04.14.17].

[31] Liang X, Lettenmaier D, Wood E, Burges S. A simple hydrologically based model of land surface water and energy fluxes for general circulation models. J Geophys Res 1994;99(14):415-514.

[32] Liang X, Wood EF, Lettenmaier DP. Surface soil moisture parameterization of the VIC-2L model: Evaluation and modification. Global Planet Change 1996;13(1):195-206. 
[33] Singh P, Jain SK. Snow and glacier melt in the Satluj River at Bhakra Dam in the western Himalayan region. Hydrol Sci J 2002;47(1):93-106.

[34] Singh P, Jain SK. Modelling of streamflow and its components for a large Himalayan basin with predominant snowmelt yields. Hydrol Sci J 2003;48(2):257-76.
[35] < http://www.cea.nic.in/executive_summary.html > [last accessed 04.14.17].

[36] < http://rredc.nrel.gov/solar/new_data/India/about.html > [last accessed 04. 14.17]. 